\title{
Modified Batista Procedure for Idiopathic Dilated Cardiomyopathy: Report of a Case
}

\author{
Keisuke Morimoto*, Hiroaki Kuroda, Kimiyo Ono, Shigeto Miyasaka, Suguru Shiraya, \\ Futoshi Kobayashi, Kengo Nishimura, Yoshikazu Fujiwara \\ Department of Cardiovascular Surgery, Sanin Rosai Hospital, Yonago, Japan \\ Email: *morimoto@saninh.johas.go.jp, kuroda@saninh.johas.go.jp, Ono@saninh.johas.go.jp, miyasaka-c@pref.tottori.jp, \\ shiraya1326@me.com, f_breeze_shore@i-next.ne.jp, nishimurakengo@hotmail.co.jp, fujifuji@med.tottori-u.ac.jp
}

How to cite this paper: Morimoto, K., Kuroda, H., Ono, K., Miyasaka, S., Shiraya, S., Kobayashi, F., Nishimura, K. and Fujiwara, Y. (2017) Modified Batista Procedure for Idiopathic Dilated Cardiomyopathy: Report of a Case. World Journal of Cardiovascular Surgery, 7, 32-40.

https://doi.org/10.4236/wjcs.2017.73005

Received: January 31, 2017

Accepted: March 17, 2017

Published: March 20, 2017

Copyright (c) 2017 by authors and Scientific Research Publishing Inc. This work is licensed under the Creative Commons Attribution International License (CC BY 4.0).

http://creativecommons.org/licenses/by/4.0/

\section{Open Access}

\begin{abstract}
The surgical indications for dilated cardiomyopathy (DCM) remain controversial, not including cardiac transplantation and mechanical circulatory support. We describe a case of idiopathic DCM that underwent successful surgical treatment using a modified left ventriculectomy, modification of the Batista procedure. The patient was a 63-year-old man who suffered from heart failure, New York Heart Association (NYHA) Class IV. Heart failure was derived from idiopathic DCM with a severely compromised left ventricular function complicated by left ventricular thrombosis. He underwent successful surgical treatment, specifically partial left ventriculectomy combined with the papillary muscle approximation, and the postoperative course was uneventful. He has been well with NYHA Class I for 3 years after the operation without heart failure.
\end{abstract}

\section{Keywords}

Batista Procedure, Left Ventriculoplasty, Idiopathic Dilated Cardiomyopathy, Left Ventriculectomy, Left Ventricular Thrombosis

\section{Introduction}

Batista and colleagues [1] [2] reported partial left ventriculectomy (PLV) as a surgical option for the treatment of patients with severe dilated cardiomyopathies (DCM). Several studies [3] [4] [5] [6] [7] showed improvements in the left ventricular (LV) function and recovery from congestive heart failure in cases of DCM after the surgical procedure. However, the procedure is associated with a high early and late failure rate [8] [9] [10]. The contradictory findings in these reports may have derived from variations in each patient population. However, the indications for performing this procedure for DCM remain controversial. 
The original method, the Batista procedure, includes partial left ventriculectomy, resection of the dilated posterolateral LV wall between the anterior and posterior papillary muscles. Occasionally, resection of a papillary muscle or bilateral papillary muscles is performed in the procedure. PLV without preservation of the mitral complex may lead to the loss of LV function improvement after the procedure. Moreover, the original procedure may be technically difficult in some cases. We herein describe a patient with idiopathic DCM who was successfully treated using modified PLV combined with papillary muscle approximation (PMA).

\section{Case Report}

The patient was a 63-year-old man. He was admitted to our hospital for congestive heart failure when he was 60 years of age. He complained of general fatigue and appetite loss. His blood pressure was $117 / 88 \mathrm{mmHg}$, and heart rate was 118 beats/min. A chest radiograph demonstrated cardiac enlargement with a cardiothoracic ratio (CTR) of 0.61 (normal range of CTR: less than 0.5 [11]) and bilateral pleural effusion (Figure 1). A twelve-lead electrocardiogram showed atrial fibrillation rhythm but not ischemic change. An echocardiograph revealed diffuse severe hypokinesis with mild mitral regurgitation (MR). He did not wish to undergo a cardiac catheter examination. He underwent a myocardial perfusion imaging SPECT study without stress protocol. The study demonstrated the diffuse accumulation declinein LV myocardiumand the diffuse severe hypokinesis of LV wall motion. Three-dimensional computed tomography scanning demonstrated that there was no significant stenosis in the coronary artery. None of his findings indicated ischemic heart disease significantly and he had no episodes of a previous

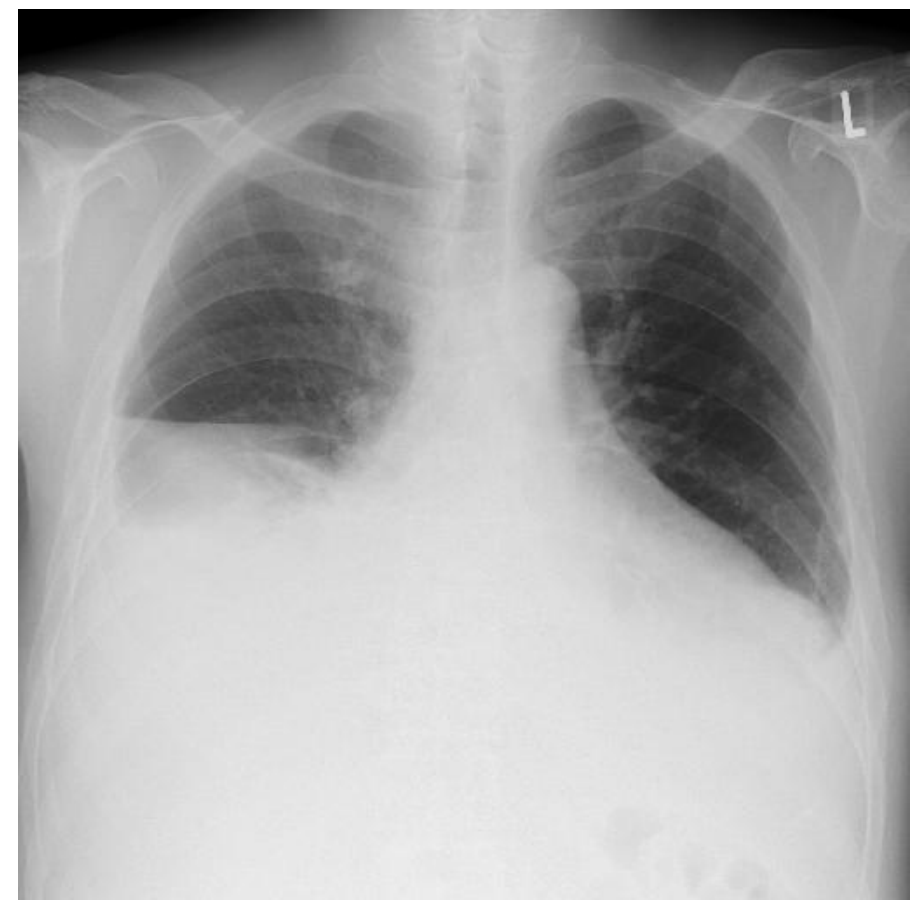

Figure 1. A chest radiograph shows cardiac enlargement with a cardiothoracic ratio of 0.61 and bilateral pleural effusion. 
myocardial infarction. He had been previously treated with medication under the potential diagnosis of idiopathic DCM. Two years later, he complained of dyspnea at rest and orthopnea and had, New York Heart Association (NYHA) class IV. He received medical treatment for worsening heart failure on admission. A chest radiograph demonstrated a CTR of 0.56 and electrocardiogram showed atrial fibrillation rhythm, heart rate of 96 beats/min. However, his heart failure was not improved. An echocardiograph showed a LV diastolic dimension of 64 $\mathrm{mm}, \mathrm{LV}$ systolic dimension of $53 \mathrm{~mm}, \mathrm{LV}$ end-diastolic volume (index) of 207 $\mathrm{ml}\left(122 \mathrm{ml} / \mathrm{m}^{2}\right)$ (normal range of LV end-diastolic volume index: from 35 to 75 $\mathrm{ml} / \mathrm{m}^{2}$ [12]), LV end-systolic volume (index) of $164 \mathrm{ml}\left(96 \mathrm{ml} / \mathrm{m}^{2}\right)$, diastolic papillary muscle distance of $39 \mathrm{~mm}$ (normal range of diastolic papillary muscle distance: $23.5 \pm 4.0 \mathrm{~mm}$ [13]), systolic papillary muscle distance of $33 \mathrm{~mm}$, and diffuse hypokinesis with a LV ejection fraction (EF) of $21 \%$ (normal range of LVEF: more than 0.55 [13]). Additionally, the echocardiograph revealed a LV thrombus at the apex, and showed mild (Grade 1) MR for mild tethering due to LV enlargement, coaptationdeapth (CD) of $9 \mathrm{~mm}$ (normal range of CD: less than $10 \mathrm{~mm}$ [14]), tenting area (TA) of $1.53 \mathrm{~cm}^{2}$ (normal range of TA: from 0.6 to $0.8 \mathrm{~cm}^{2}$ [15]) and posterolateral angle (PA) of 45 degrees (normal range of PA: less than 45 degrees [14]) (Figure 2). An informed consent was taken from the patient for surgery and for subsequent reporting of the case. A cardiopulmonary bypass (CPB) under mild systemic hypothermia was performed. The volume reduction test [16] was performed, which shows changes in LV wall motion and thickness that can be observed using transesophageal or epicardial echocardiography when the left ventricle is decompressed on $\mathrm{CPB}$. We confirmed that the contraction of the left ventricle was diffuse hypokinetic and that localization of the changes in the LV wall thickness was not observed. After cross-clamping of the distal ascending aorta, cardiac arrest was accomplished by initial antegrade cold blood cardioplegia

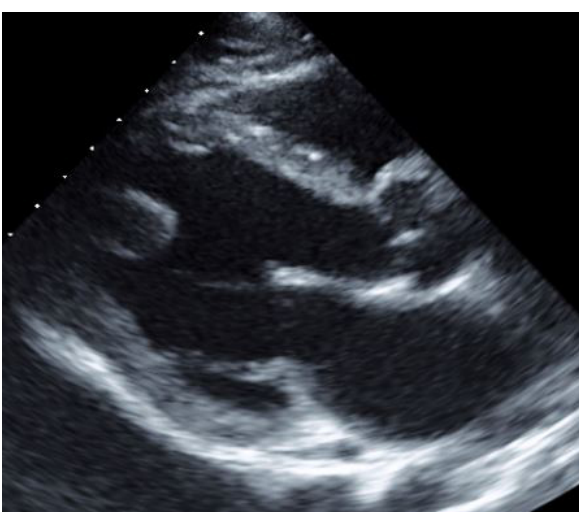

(a)

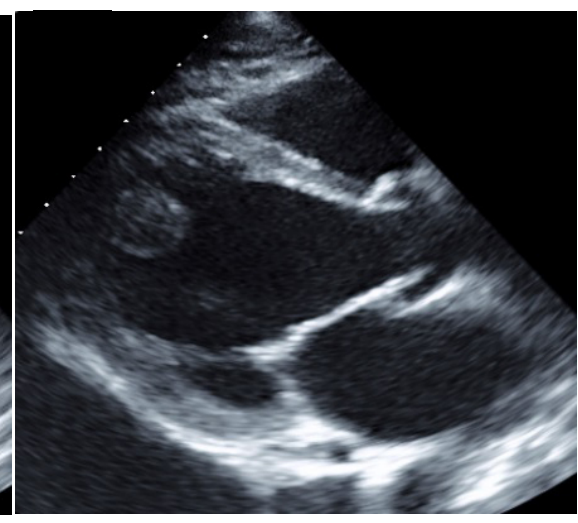

(b)

Figure 2. A preoperative echocardiograph shows a dilated left ventricle with diffuse hypokinesis and leaflet tethering of the mitral valve. The left ventricular (LV) ejection fraction was $21 \%$. There was a LV thrombus at the apex. (a) Diastole. The LV diastolic dimension is $64 \mathrm{~mm}$ and the $\mathrm{LV}$ end-diastolic volume (index) is $207 \mathrm{ml}\left(122 \mathrm{ml} / \mathrm{m}^{2}\right)$. (b) Systole. The LV systolic dimension is $53 \mathrm{~mm}$ and the LV end-systolic volume (index) is $164 \mathrm{ml}$ (96 $\mathrm{ml} / \mathrm{m}^{2}$ ). 
via the aortic root and continuous retrograde cold blood cardioplegia. Left anterior ventriculectomy was made $1.5 \mathrm{~cm}$ lateral and parallel to the left anterior descending artery (LAD). The partial resection of the left ventricle was a spindleshaped slice of $1.5 \mathrm{~cm} \times 4.0 \mathrm{~cm}$. The incision was extended from the distal area of the diagonal branch to the area just proximal to the LV apex, and its dimension was approximately $5 \mathrm{~cm}$. There was a restiform thrombus at the LV apex, and it was removed. PMA [17] was carried out with two 2 - 0 braided mattress sutures buttressed with pledgets. These sutures were placed on the heads and bases of the anterior and posterior papillary muscles, and plication of the posterolateral wall was performed. Ventriculectomy was closed using a mattress suture with a Teflon felt strip on either side of the incision (Figure 3). The patient was smoothly weaned from the CPB. The duration of the CPB and aortic cross clamp was 106 minutes and 49 minutes, respectively. The postoperative course was uneventful and he was discharged on the 33th postoperative day. The pathology of the resected LV wall was compatible with idiopathic DCM. A postoperative echocardiograph showed a LV diastolic dimension of $50 \mathrm{~mm}$, LV systolic dimension of 38 $\mathrm{mm}, \mathrm{LV}$ end-diastolic volume (index) of $123 \mathrm{ml}\left(72 \mathrm{ml} / \mathrm{m}^{2}\right)$, LV end-systolic volume (index) of $88 \mathrm{ml}\left(52 \mathrm{ml} / \mathrm{m}^{2}\right)$, diastolic papillary muscle distance of $20 \mathrm{~mm}$, systolic papillary muscle distance of $17 \mathrm{~mm}$, LV ejection fraction (EF) of $28 \%$, and trivial MR without tethering (Figure 4). Further, the LV diastolic dimension, LV systolic dimension, and LV EF after the surgery were $62 \mathrm{~mm}, 50 \mathrm{~mm}$, and 38\%, respectively, at 15 months; and $59 \mathrm{~mm}, 55 \mathrm{~mm}$, and $31 \%$, respectively, at 25 months; and $61 \mathrm{~mm}, 45 \mathrm{~mm}$, and $42 \%$, respectively, at 32 months. The MR was trivial or mild (Grade 1) throughout the entire period. The patient has been well with NYHA class I for 3 years after the operation without heart failure.

\section{Discussion}

Despite recent advances in the management of patients with heart failure, morbidity and mortality rates for patients with severe DCM remain high. The prognosis of the patients is related to the severity of disease at initial presentation. A standard heart failure regimen should be initiated in the patients, including angiotensin-converting-enzyme inhibitors, angiotensin-II receptor antagonists, beta-blockers, diuretics, aldosterone antagonists, and digitalis. In some select patients known with rhythm disturbances and/or increased risk of sudden cardiac death, resynchronization therapy combined with an implantable cardioverter device should be considered to reduce morbidity and mortality. The prognosis of end-stage DCM with resistance to medical therapies is poor without surgical treatments. Surgical management for idiopathic DCM includes heart transplantation and mechanical circulatory support. However, there is a limited supply of hearts available for transplantation. As a surgical therapeutic option for the treatment of patients with end-stage DCM, PLV was first reported by Batista et al in 1996 [1]. Some studies [8] [9] [10] demonstrated that the procedure was associated with high incidences of heart failure in the early postoperative period and that the longterm clinical outcomes were unfavorable. On the other hand, some acceptable 


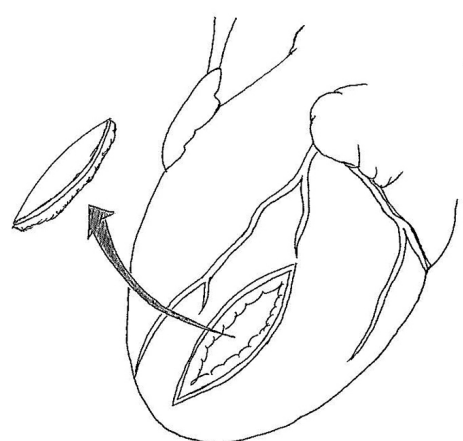

(a)

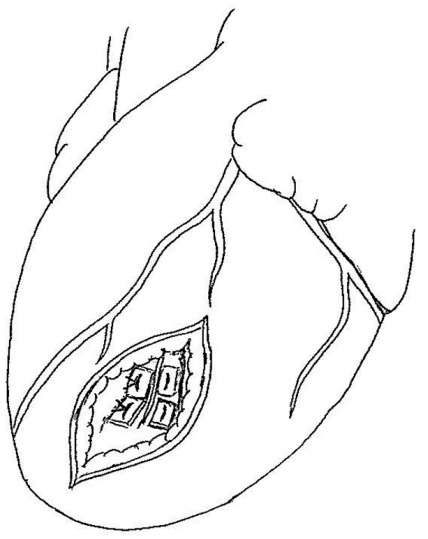

(c)

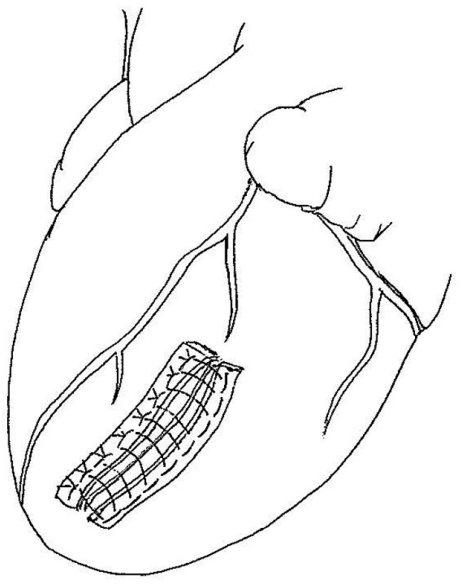

(e)

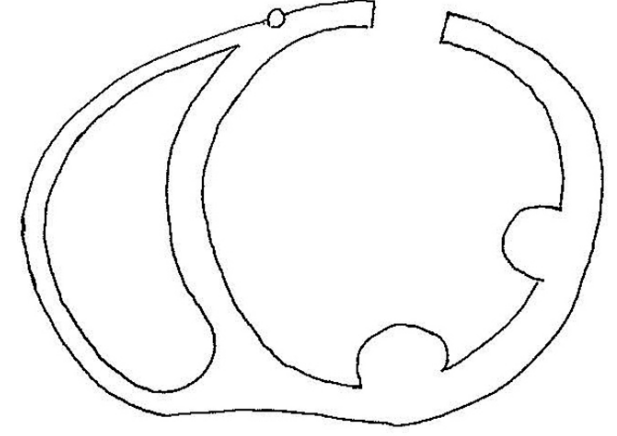

(b)

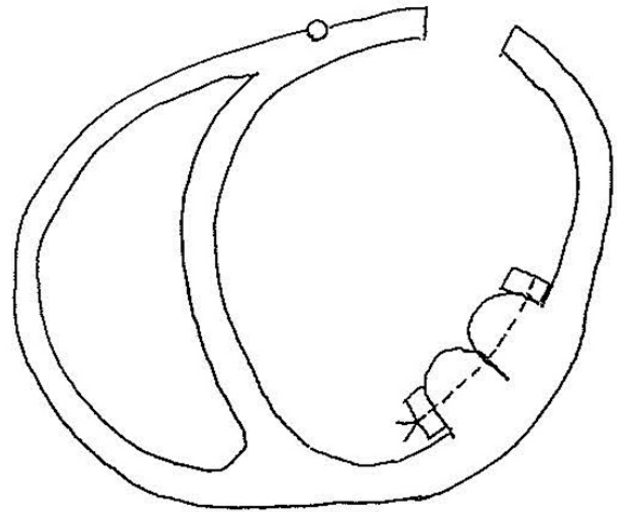

(d)

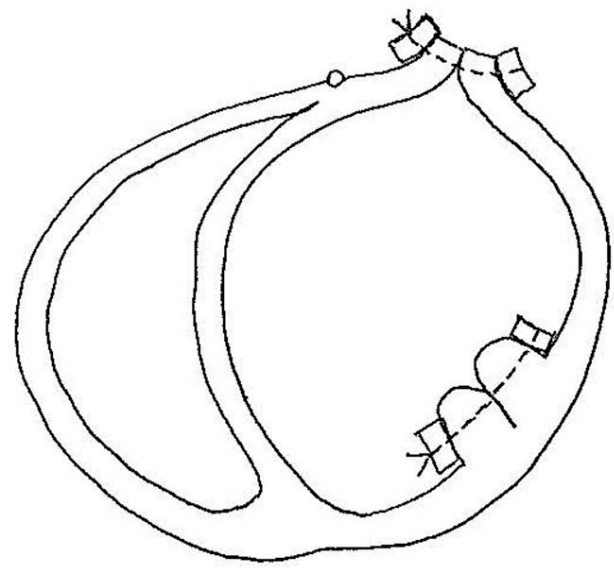

(f)

Figure 3. A schematic illustration shows partial left ventriculectomy (a) (b) with papillary muscles approximation (PMA). The sutures for PMA are placed on the heads and bases of the anterior and posterior papillary muscles, and plication of the posterolateral wall is performed (c) (d). Ventriculectomy is closed using a mattress suture with a Teflon felt strip on either side of the incision (e) (f).

outcomes have been reported in four patients who underwent the improved procedures [18] [19] [20] [21]. The differences in the outcomes in the reports may be related to the patient selection. Depending on the patient profiles and disease 


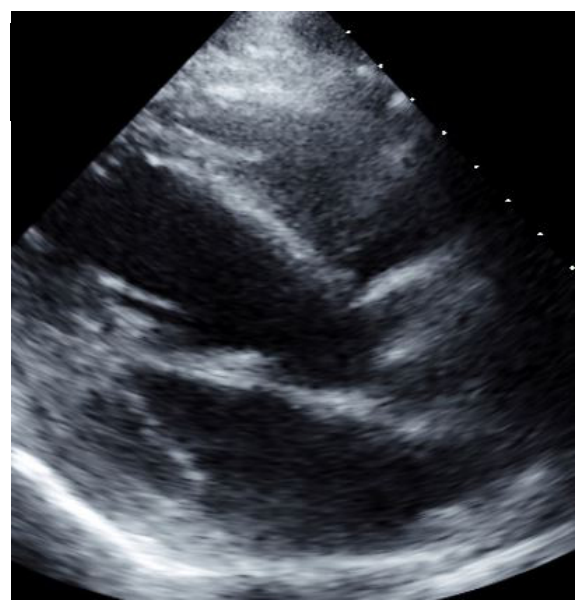

(a)

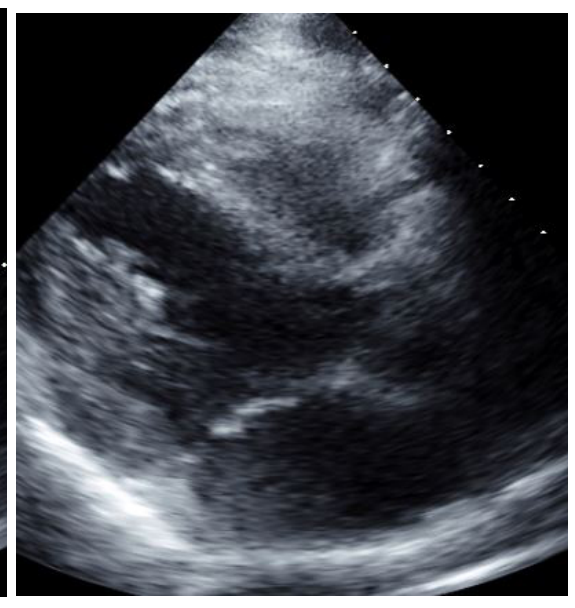

(b)

Figure 4. A postoperative echocardiograph shows that the left ventricular (LV) geometry and the LV volume are normalized. The LV ejection fraction is $28 \%$ and leaflet tethering of the mitral valve disappear. (a) Diastole. The LV diastolic dimension is $50 \mathrm{~mm}$ and LV end-diastolic volume (index) is $123 \mathrm{ml}\left(72 \mathrm{ml} / \mathrm{m}^{2}\right)$. (b) Systole. The LV systolic dimension is $38 \mathrm{~mm}$ and the $\mathrm{LV}$ end-systolic volume (index) is $88 \mathrm{ml}\left(52 \mathrm{ml} / \mathrm{m}^{2}\right)$.

states, appropriate patient selection may be important. In advanced heart failure patients undergoing cardiac transplantation and mechanical circulatory support, the Interagency Registry for Mechanically Circulatory Support (INTERMACS) profiles have been proposed to estimate the potential for severe heart failure [22] [23] [24]. These profiles could be helpful for patient selection for left ventricular plasty (LVP) in the treatment of patients with severe DCM. Our case would be classified into profile 4 according to the IMTERMACS profiles.

Frazier et al. [25] reported that patients undergoing PLV with better clinical outcome had less myocyte hypertrophy and fibrosis. Furthermore, Moreira et al. [8] demonstrated the actuarial survival according to LV myocytes hypertrophy, a factor that was identified to be a predictor of early mortality after PLV. The difference of outcomes in some clinical reports on PLV may have been related to structural remodeling of the heart. The pathology of the resected LV wall in the present patient was compatible with idiopathic DCM, and the pathological result showed mild myocyte hypertrophy and fibrosis. The indication for LVP for DCM is controversial. However, the adequate selection of patients with DCM for LVP could bring successful results. The present patient had DCM complicated by left ventricular thrombosis with resting symptoms on oral therapy and he did not have severe complications. We considered that the patient would be able to undergo surgery before the operation; therefore, we performed the surgical treatment using modified PLV.

In the original Batista procedure [1], the posterolateral wall of the left ventricle is widely resected. Some patients undergoing the procedure lose the coronary arteries, papillary muscles and mitral complex due to PVL. Therefore, the procedure may cause partial myocardial ischemia of the left ventricle and dysfunction of the papillary muscle and mitral valve. Additionally, it has been demonstrated that the extent of interstitial fibrosis and the decreased myocardial con- 
traction area in the left ventricle are not uniform in advanced idiopathic DCM [26]. Suma et al. [19] reported their eight-year experience with the septal anterior ventricular exclusion (SAVE) procedure for congestive heart failure due to idiopathic DCM. They concluded that the SAVE procedure with mitral reconstruction is a useful option for the treatment of advanced idiopathic DCM in severely dilated left ventricle with an akinetic septum. The SAVE procedure is considered to adapt to patients with dysfunction of the anteroseptal LV wall in DCM. Isomura et al. [21] showed that the posterior restoration in patients with posterolateralakinesis and septal kinesis improved the operative and mid-term results in selected patients with DCM. A procedure with as little myocardial resection as possible would be expected in patients with diffuse hypokinesis of the LV wall motion in severe DCM. Matsui et al. [18] reported the usefulness of integrated overlapping ventriculoplasty combined with papillary muscle plication for severely dilated heart failure. Suma et al. [16] have showed that an intraoperative echographic evaluation is important for the purpose of proper site selection for ventricular reduction in end-stage cardiomyopathy. We performed an intraoperative echographic evaluation under the $\mathrm{CPB}$ in the present case, and confirmed that the contraction of the left ventricle was diffuse hypokinetic, especially severe hypokinetic in the anteroseptal wall, and that localization of changes in the LV wall thickness could not be observed. Therefore, we determined the site of resection in the anterior wall. Furthermore, our patient was considered to be unsuitable for overlapping ventriculoplasty due to moderate LV dilatation and the relative LV wall thickness. Nishina et al. [20] reported the importance of apex-sparing PLV on the LV geometry, function, and long-term survival of patients with endstage DCM. We performed left ventriculectomy in the LV anterior wall with apexsparing LVP and posterolateral LV wall preserving LVP with PMA. The resection area in the anterior wall, the seam allowance in anterior wall after resection and papillary muscle approximation resulted in the reduction of left ventricular diameter. Therefore, the LV geometry and the LV volume in the present patient were normalized by our procedure. Our results are comparable to the reports of the households.In cases with moderate or severe functional MR due to leaflet tethering of the mitral valve, mitral valve annuloplasty with PMA would be necessary. In the present patient, MR due to leaflet tethering was mild (grade I) and the dilation of the mitral valve annulus was slight. Therefore, PMA without mitral valve annuloplasty was performed in the present case. Furthermore, the procedure led to the disappearance of the leaflet tethering of the mitral valve and trivial MR. The patient has had a good postoperative course without heart failure in the midterm follow-up.Our procedure is a recommended technique as an indication for LVPin the case of DCM with mild MR or without MR, and with dysfunction of anterior or diffuse LV wall motion.

\section{Conclusion}

We report a case of idiopathic DCM that underwent successful surgical treatment using a modified left ventriculectomy, specifically partial left ventriculectomy combined with the papillary muscle approximation. This procedure is techni- 
cally easy and can be effective for the surgical treatment of idiopathic DCM.

\section{References}

[1] Batista, R.J.V., Santos, J.L., Takeshita, N., Bocchino, L., Lima, P.N. and Cunha, M.A. (1996) Partial Left Ventriculectomy to Improve Left Ventricular Function in EndStage Heart Disease. Journal of Cardiac Surgery, 11, 96-97. https://doi.org/10.1111/j.1540-8191.1996.tb00019.x

[2] Batista, R.J.V., Verde, J., Nery, P., Bocchino, L., Takeshita, N., Bhayana, J.N., et al. (1997) Partial Left Ventriculectomy to Treat End-Stage Heart Disease. Annals of Thoracic Surgery, 64, 634-638. https://doi.org/10.1016/S0003-4975(97)00779-0

[3] McCarthy, P.M., Starling, R.C., Wong, J., Scalia, G.M., Buda, T., Vargo, R.L., et al. (1997) Early Results with Partial Left Ventriculectomy. Journal of Thoracic and Cardiovascular Surgery, 114, 755-763. https://doi.org/10.1016/S0022-5223(97)70079-5

[4] Angelini, G.D., Pryn, S., Mehta, D., Izzat, M.B., Walsh, C., Wilde, P., et al. (1997) Left-Ventricular-Volume Reduction for End-Stage Heart Failure. Lancet, 350, 489. https://doi.org/10.1016/S0140-6736(97)24033-X

[5] Moreira, L.F.P., Stolf, N.A.G., Bocchi, E.A., Bacal, F., Giorgi, M.C.P., Parga, J.R., et al. (1998) Partial Left Ventriculectomy with Mitral Valve Preservation in the Treatment of Patients with Dilated Cardiomyopathy. Journal of Thoracic and Cardiovascular Surgery, 115, 800-807. https://doi.org/10.1016/S0022-5223(98)70358-7

[6] Suma, H., Isomura, T., Horii, T., Sato, T., Kikuchi, N., Iwahashi, K., et al. (1998) Two-Year Experience of the Batista Operation for non-Ischemic Cardiomyopathy. Journal of Cardiology, 32, 269-276.

[7] Gradinac, S., Miric, M., Popovic, Z., Popovic, A., Neskovic, A., Jovovic, L., et al. (1998) Partial Left Ventriculectomy for Idiopathic Dilated Cardiomyopathy: Early Results and Six-Month Follow-Up. Annals of Thoracic Surgery, 66, 1963-1968. https://doi.org/10.1016/S0003-4975(98)00888-1

[8] Moreira, L.F.P., Stolf, N.A.G., Higuchi, M.L., Bacal, F., Bocchi, E.A. and Oliveira, S.A. (2000) Current Perspectives of Partial Left Ventriculectomy in the Treatment of Dileted Cardiomyopathy. European Journal of Cardio-Thoracic Surgery, 19, 54 60. https://doi.org/10.1016/S1010-7940(00)00617-5

[9] Cereceda, A.F., McCarthy, P.M., Blackstone, E.H., Hoercher, K.J., White, J.W., Young, J.B., et al. (2001) Partial Left Ventriculectomy for Dilated Cardiomyopathy: Is This Alternative to Transplantation? Journal of Thoracic and Cardiovascular Surgery, 121, 879-893. https://doi.org/10.1067/mtc.2001.113598

[10] Tonnessen, T. and Knudsen, C.W. (2005) Surgical Left Ventricular Remodeling in Heart Failure. European Journal of Heart Failure, 7, 704-709.

https://doi.org/10.1016/j.ejheart.2005.07.005

[11] Rubens, M. (1996) The Chest X-Ray in Adult Heart Disease. In: Julian, D., Camm, A.J., Fox, K.M., Hall, R.J.C. and Poole-Wilson, P.A., Eds., Diseases of the Heart, 2nd Edition, London, Saunders, 253-283.

[12] Armstrong, W.F. and Ryan, T. (2010) Evaluation of Systolic Function of the Left Ventricle. In: Armstrong, W.F. and Ryan, T., Eds., Feigenbaum's Echocardiography, 7th Edition, Philadelphia, Lippincott Williams \& Wilkins, 123.

[13] Lang, R.M., Bierig, M., Devereux, R.B., Flachskampf, F.A., Foster, E., Pellikka, P.A., et al. (2006) Recommendations for Chamber Quantification. European Journal of Echocardiography, 7, 79-108. https://doi.org/10.1016/j.euje.2005.12.014

[14] Lancellotti, P., Moura, L., Pierard, L.A., Agricola, E., Popescu, B.A., Tribouilloy, C., 
et al. (2010) European Association of Echocardiography Recommendations for the Assessment of Valvular Regurgitation. Part 2: Mitral and Tricuspid Regurgitation (Native Valve Disease). European Journal of Echocardiography, 11, 307-332. https://doi.org/10.1093/ejechocard/jeq031

[15] Dudzinski, D.M. and Hung, J. (2014) Echocardiographic Assessment of Ischemic Mitral Regurgitation. Cardiovasc Ultrasound, 12, 46. https://doi.org/10.1186/1476-7120-12-46

[16] Suma, H., Isomura, T., Horii, T., Sato, T., Kikuchi, N., Iwahashi, K., et al. (2000) Nontransplant Cardiac Surgery for End-Stage Cardiomyopathy. Journal of Thoracic and Cardiovascular Surgery, 119, 1233-1245. https://doi.org/10.1067/mtc.2000.106520

[17] Matsui, Y., Suto, Y., Shimura, S., Fukada, Y., Naito, Y., Yasuda, K., et al. (2005) Impact of Papillary Muscles Approximation on the Adequacy of Mitral Coaptation in Functional Mitral Regurgitation Due to Dilated Cardiomyopathy. Annals of Thoracic and Cardiovascular Surgery, 11, 164-171.

[18] Matsui, Y., Fukada, Y., Naito, Y. and Sasaki, S. (2004) Integrated Overlapping Ventriculoplasty Combined with Papillary Muscle Plication for Severely Dilated Heart Failure. Journal of Thoracic and Cardiovascular Surgery, 127, 1221-1223. https://doi.org/10.1016/j.jtcvs.2003.10.044

[19] Suma, H., Isomura, T., Horii, T. and Nomura, F. (2006) Septal Anterior Ventricular Exclusion Procedure for Idiopathic Dilated Cardiomyopathy. Annals of Thoracic Surgery, 82, 1344-1348. https://doi.org/10.1016/j.athoracsur.2006.04.096

[20] Nishina, T., Shimamoto, T., Marui, A. and Komeda, M. (2009) Impact of ApexSparing Partial Left Ventriculectomy on Left Ventricular Geometry, Function, and Long-Term Survival of Patients with End-Stage Dilated Cardiomyopathy. Journal of Cardiac Surgery, 24, 499-502. https://doi.org/10.1111/j.1540-8191.2009.00874.x

[21] Isomura, T., Notomi, Y., Hoshino, J., Fukada, Y., Katahira, S., Kitamura, A., et al. (2010) Indication of Posterior Restoration and Surgical Results in Patients with Dilated Cardiomyopathy. European Journal of Cardio-Thoracic Surgery, 38, 171-175. https://doi.org/10.1016/j.ejcts.2009.12.028

[22] Stevenson, L.W., Pagani, F.D., Young, J.B., Jessup, M., Miller, L., Kormos, R.L., et al. (2009) INTERMACS Profiles of Advanced Heart Failure: The Current Picture. Journal of Heart and Lung Transplantation, 28, 535-541.

https://doi.org/10.1016/j.healun.2009.02.015

[23] Alba, A.C., Rao, V., Ivanov, J., Ross, H.J. and Delgado, D.H. (2009) Usefulness of the INTERMACS Scale to Predict Outcomes after Mechanical Assist Device Implantation. Journal of Heart and Lung Transplantation, 28, 827-833. https://doi.org/10.1016/j.healun.2009.04.033

[24] Peura, J.L., Covin-Adams, M., Francis, G.S., Grady, K.L., Hoffman, T.M., Jessup, M., et al. (2012) Recommendations for the Use of Mechanical Circulatory Support: Device Strategies and Patient Selection. Circulation, 27, 2648-2667. https://doi.org/10.1161/CIR.0b013e3182769a54

[25] Frazier, O.H., Gradinac, S., Segura, A.M., Przybylowski, P., Popovic, Z., Vasiljevic, J., et al. (2000) Partial Left Ventriculectomy: Which Patients Can Be Expected to Benefit? Annals of Thoracic Surgery, 69, 1836-1841. https://doi.org/10.1016/S0003-4975(00)01344-8

[26] Suma, H. (2001) Left Ventriculoplasty for Nonischemic Dilated Cardiomyopathy. Seminars in Thoracic and Cardiovascular Surgery, 13, 514-522. https://doi.org/10.1053/stcs.2001.30131 
Submit or recommend next manuscript to SCIRP and we will provide best service for you:

Accepting pre-submission inquiries through Email, Facebook, LinkedIn, Twitter, etc. A wide selection of journals (inclusive of 9 subjects, more than 200 journals)

Providing 24-hour high-quality service

User-friendly online submission system

Fair and swift peer-review system

Efficient typesetting and proofreading procedure

Display of the result of downloads and visits, as well as the number of cited articles Maximum dissemination of your research work

Submit your manuscript at: http://papersubmission.scirp.org/

Or contact wjcs@scirp.org 